\title{
Gaz Yakıtlı Kombi Sistemlerin Mikrodenetleyici Yardımıyla Kontrolü ve Enerji Verimliliği
}

\author{
Volkan ŞAHIN ${ }^{1}$, Mehmet Erhan ŞAHIN ${ }^{2}$ \\ ${ }^{1}$ Dr. Lecturer, Isparta University of Applied Sciences University, Keçiborlu Vocational High School, Machine \\ and Metal Technologies Departmant, Isparta, Turkey \\ ${ }^{2}$ Dr. Lecturer, Isparta University of Applied Sciences University, Technical Sciences Vocational High School, \\ Biomedical Devices Technologies Departmant, Isparta, Turkey
}

Geliş Tarihi/Received: 13.01.2021

Kabul Tarihi/Accepted: 26.02.2021
Doi: 10.31200/makuubd.860193

Araştırma Makalesi/Research Article

\section{ÖZET}

Günümüzde enerji kullanımının ve enerji maliyetlerinin arttığı göz önünde bulundurularak, enerjinin tüketildiği yerlerde enerjinin verimli kullanımı büyük önem kazanmıştır. Bilinçsizce tüketilen enerji, enerji kaynaklarına ve ekolojik açıdan doğaya zarar vermektedir. Bundan dolayı tüketilmekte olan enerjinin yönetilmesine ihtiyaç duyulmaktadır. Kullanıcıların, çoğu zaman farkında olmadan ihtiyacından daha fazla enerji tükettikleri görülmektedir. Enerji yönetiminin amac1, enerji tüketimini azaltmak yerine, enerjiyi daha verimli biçimde kullanabilmektir. Etkin bir enerji yönetimi sayesinde, enerji kaynaklarının kullanım ömrünün uzatılması, enerjinin verimli kullanılması ve enerji maliyetlerinin düşürülmesi sağlanmış olacaktır. Bu çalışma, doğal gaz yakıt enerjisi kullanarak 1sı enerjisi üreten kombi sistemine uyarlanmıştır. Kombi sistemine entegre edilen mikrodenetleyici kullanılarak radyatör ve oda sıcaklıkları manuel veya otomatik hale getirilerek tüketilen doğalgaz enerjisinin daha verimli tüketilmesi böylelikle tasarruf edilmesi amaçlanmıştır.

Anahtar kelimeler: Enerji Yönetimi, Isıtma Sistemi, Mikrodenetleyici, Otomasyon. 


\title{
Control of Gas Fired Combi Systems with the Help of Microcontroller and Energy Efficiency
}

\begin{abstract}
Considering the increase in energy use and energy costs today, efficient use of energy has gained great importance in places where energy is consumed. Unconsciously consumed energy harms energy resources and ecologically nature. Therefore, there is a need to manage the energy consumed. It is seen that users consume more energy than they need, often without realizing it. The purpose of energy management is to use energy more efficiently instead of reducing energy consumption. Thanks to an effective energy management, it will be provided to extend the life of energy resources, to use energy efficiently and to reduce energy costs. This study is adapted to the boiler system that generates heat energy by using natural gas fuel energy. Using the microcontroller integrated into the boiler system, it is aimed to save the natural gas energy consumed more efficiently by making the radiator and room temperatures manual or automatic.
\end{abstract}

Keywords: Energy management, Heating meeting, Microcontroller, Automation.

\section{GIRIŞ}

$\mathrm{Bu}$ güne kadar dünyada ortaya çıkan enerji krizleri, enerjinin verimli bir şekilde kullanılması gerektiğini göstermiştir. Bundan dolayı, endüstriyel gelişmelere bağlı olarak, artan enerji talebinin karşılanması için değişik enerji türlerinin ortaya çıkmasını ve bunların en verimli bir şekilde kullanılması gerekliliğini doğurmuştur. Bu bağlamda enerjinin en verimli biçimde kullanılması için nelerin yapılabileceği hususu dünyada en çok tartışılan konuların başında gelmektedir. Dolayısıyla enerji üretiminin kendine özgü zorlukları vardır. Aynı şekilde enerjinin en verimli biçimde tüketimi de ayrı zorluklar içermektedir (Christoffersen vd., 2006; Chen vd., 2005; Şahin vd., 2017; Kolokotsa vd., 2002).

Enerji maliyetlerinin her geçen gün artması nedeniyle, enerjinin rantabıl kullanımı, her geçen gün biraz daha önem kazanmaktadır. Enerji - Çevre ilişkisinin yanı sıra, kaynakların hızla tükeniyor olması, enerji yönetimi konusunun önemini daha da arttırmaktadır (Hepbasli ve Ozalp, 2003). Gün geçtikçe Türkiye'nin de enerji tüketimi hızlı bir şekilde artmaktadır. Bu da doğal enerji kaynaklarımızın verimsiz ve büyük bir hızla tüketilmekte olduğu sonucunu ortaya çıkarmaktadır (Ardehali vd., 2004). Enerji tüketimi sonucunda her türlü katı, sıvı ve gaz atıkların neden olduğu ekolojik sorunlar ortaya çıkmış ve hızlı bir şekilde artan çevresel 
problemlerin önlenmesi konusunda yeni arayışları doğurmuştur (Zhelev, 2005; Karagiorgasa vd., 2006).

Enerjinin büyük bir kısmının, ileri teknoloji ürünlerinin kullanıldığı enerji tasarruf önlemleriyle geri kazanılabileceği öngörülmektedir. Bu kapsamda tüketilen enerjinin tüketim profilinin bilinmesi ve enerji tüketiminin doğru yönetilmesinin gerekliliği ortaya çıkmaktadır. Enerji yönetiminde doğru ve kaliteli veri akışı oldukça önemli bir faktördür. Enerjinin etkin yönetimi onun verimli kullanımını da sağlamış olacaktır. Enerjiden tasarruf edilerek ülkenin enerji darboğazından kurtulmasına katkı sağlanacaktır (Curtis ve Khare, 2004; Önüt ve Soner, 2006).

Binalarımızın coğrafi konumları belediye imar planları parselizasyonlarından dolayı farklı yönlerde olabilmektedir. Yine bina konumlarına bağlı olarak dairelerin mimari ve mekanik tesisat projeleri farkl1l1k göstermektedir. Bir binada bulunan dairelerin oda konumları güney, kuzey, batı, doğu yönlerine denk gelebilmektedir. $\mathrm{Bu}$ da odalarda sıcaklık farklılıklarının oluşmasına sebep olmaktadır. Bu sıcaklık farklılığından kaynaklı olarak da dairelerin ortalama 1sı seviyeleri değişkenlik göstermektedir.

Bu çalışmada doğalgaz yakıtlı kombi sistemi ile ısı enerjisi üreten bir evde oda sıcaklığ nem, petek sıcaklığı, sistemin basınç değerleri ölçümleri yapılarak uzaktan kontrol edilmiştir. $\mathrm{Bu}$ parametrelere göre optimizasyon tekniği ile radyatör girişinde bulunan selenoid vanaların açma kapama kontrolleri yapılarak üretilen enerjinin en verimli şekilde kullanması amaçlanmıştır.

\section{KAVRAMSAL ÇERÇEVE}

\section{1. Ölçüm Düzeneğinin Tasarımı}

Gaz yakıtlı 1sıtma sistemlerinin daha verimli çalışabilmesi için, odalardaki nem, sıcaklık, sistem basıncı değerleri dikkate alınarak kablosuz şekilde uzaktan kontrol edilebilen ve sistemin harcadığı yakıt miktarını ölçebilen, sıcaklık değerlerini ve tüketilen yakıt miktarının ayarlanmasını kontrol edebilen bir otomasyon sistemi tasarlanmıştır.

Ölçüm sistemi için geliştirilen düzenekte; oturma odası, salon, çocuk odası, mutfak, yatak odası için 4 adet verici, kombi için 1 adet alıcı ünitesinden oluşmaktadır. Üniteler arası haberleşme nRF24L01 RF kablosuz iletişim modülü ve Arduino Uno mikrodenetleyicisi ile 
Şahin, V. \& Şahin, M. E.

gerçekleştirilmektedir. Ortam ve radyatör sıcaklık, nem verileri DHT22 sensörü ile alınmaktadır.

nRF24L01 radyo frekansı kullanarak kablosuz haberleşmeyi sağlayan bir çiptir (Şekil 1). Alıcı ve verici olarak $2.4 \mathrm{GHz}$ frekans bandında çalışmaktadır. SPI haberleşme protokolü vasıtasıyla mikrodenetleyicilerle haberleşmektedir. $2.4 \mathrm{GHz}$ frekans bandında çalışması ve düşük güç tüketimi ile avantaj sağlamaktadır (Liu vd, 2016).

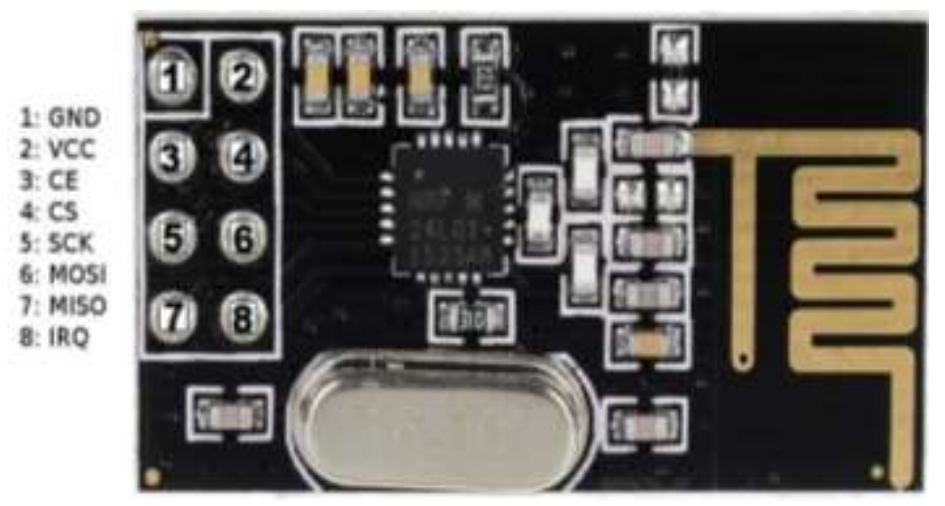

Şekil 1. nRF24L01 modülü ve pin yapıs1

Arduino Uno 2010 y1lında insanların kullanımına sunulan ve ATmega328 mikrodenetleyicisini kullanan açık kaynaklı elektronik donanım ve yazılım temelli bir geliştirme platformudur. Arduino Uno $16 \mathrm{Mhz}$ kristal osilatörü ile çalışmaktadır. 14 adet digital giriş/çıkış pinine sahiptir. Bu pinlerden 6 tanesi PWM çıkışı olarak da kullanılabilmektedir. Ayrıca 6 adet analog giriş pini vardır. USB bağlantısı ile programlanabilir ve beslenebilir. Ayrıca power jakı ile de beslenebilmektedir. Çevresiyle etkileşimde bulunarak interaktif nesneler oluşturulabilmektedir (Badamasi, 2014). Şekil 2' de RF modem Arduino bağlantısı görülmektedir.

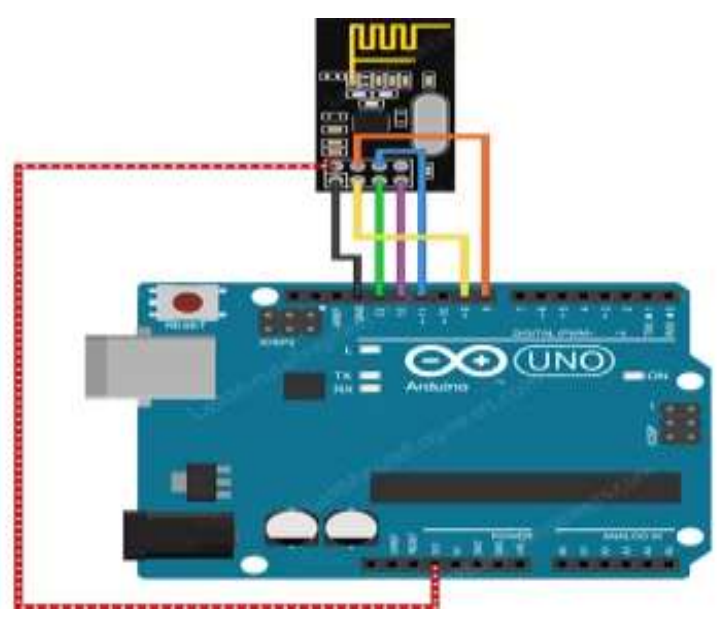

Şekil 2. nRF24L01 RF modem Arduino Uno bağlantıs1 
DHT22 sıcaklık ve nem ölçebilen dijital çıkış veren gelişmiş bir sensördür. Üzerinde 8 bitlik mikrodenetleyici bulunmaktadır. 3.3-5V, çalışma gerilimine, 1-1.5mA çalışma akımına sahiptir. -40 ile $80^{\circ} \mathrm{C}$ arasında $+/-1{ }^{\circ} \mathrm{C}$ hata payı ile sicaklık, $0-100 \% \mathrm{RH}$ arasinda $+/-5 \% \mathrm{RH}$ hata payı ile nem ölçümü yapabilmektedir. Kısa tepki süresine sahiptir. Hassas ölçüm yapabilmektedir (Aosong Electronics, 2010). Şekil 3' de pin yapısı gösterilmiştir.

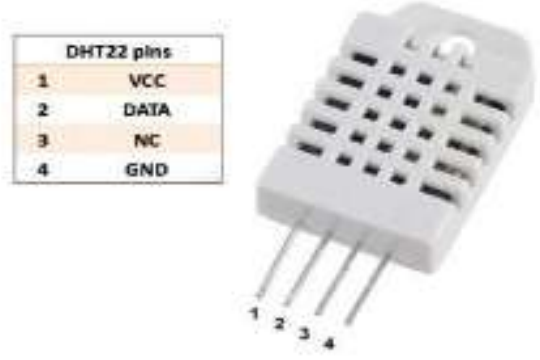

Şekil 3. DHT22 sensörü ve pin yapıs1

Ölçüm sistemimizde bulunan alıcı ünitesi, verici ünitelerinde gelen bilgileri alarak bilgisayara aktarılmasını ve bilgisayar üzerinde bulunan yazılım ile ayarlanan sıcaklık değerlerini verici ünitelerine geri bildirim yaparak selenoid vanaların açılıp kapanmasını kontrol etmektedir. Alıcı ünitesi Şekil 4'de şematik olarak gösterilmiştir.

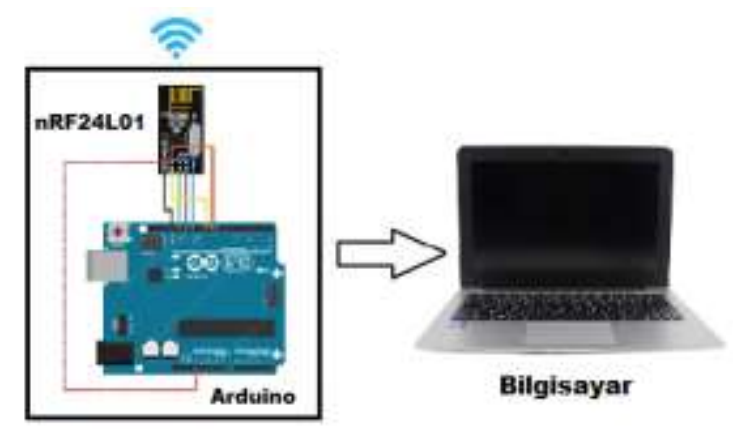

Şekil 4. Alıcı ünitesi

Birinci verici ünitesi mahallinde yer alan ısıtma sistemini ve burada bulunan peteği kontrol etmek için gaz yakıtlı kombinin yanına yerleştirilmiştir. Bu ünite ile kombinin yaktığ yakıt miktarı ve basıncı, burada bulunan radyatör sıcaklığı, ortam sıcaklığı ve nem verileri algılanabilmektedir. Aynı zamanda kombinin açılması veya kapanması kontrol edilebilmektedir. Verici ünitesi Şekil 5'de şematik olarak gösterilmiştir. 


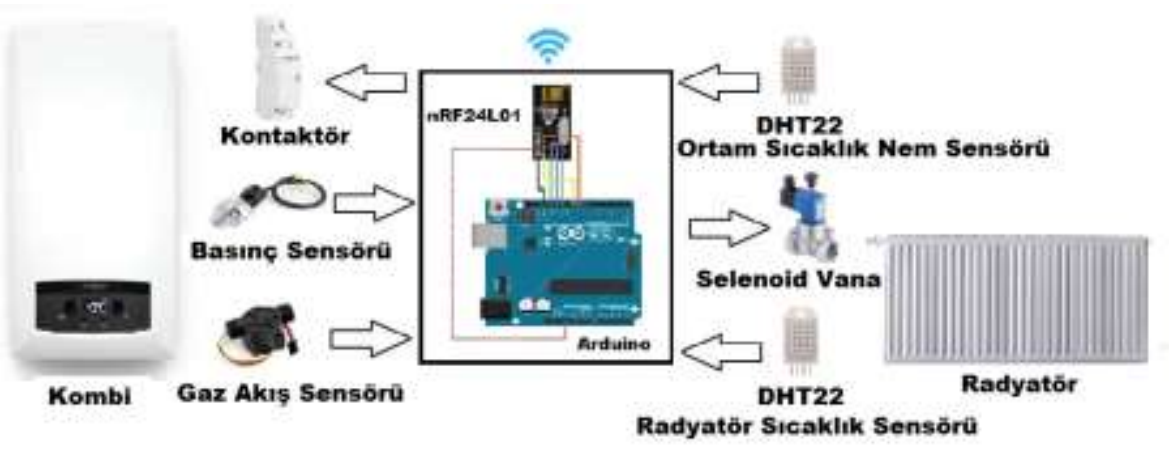

Şekil 5. Verici ünitesi

Oturma odası, çocuk odası, yatak odası, salonda bulunan diğer verici üniteleri Şekil 6' da olduğu gibi petek sıcaklı̆̆ı, ortam sıcaklığı ve nem değerlerini alıcı ünitesine göndermektedir. Aynı zamanda radyatörün sıcak su girişine bağlı bulunan selenoid vanayı kontrol ederek giren sıcak su miktarını kontrol etmektedir.



Şekil 6. Diğer verici ünitesi

Kablosuz olarak alınan verilerin görüntülenebilmesi, verilerin kayıt edilebilmesi ve sistemin kontrol edilebilmesi için bir bilgisayar programı $\mathrm{C} \#$ programlama dilinde yazılmıştır. Bilgisayar programının arayüz görüntülü Şekil 7'de olduğu gibidir. Bu yazılım ile tüm ünitelerden gelen veriler görüntülenebilmektedir. İstenirse farklı zaman periyotlarında (saat, hafta, ay vb.) kayıt altına alınabilmektedir. Bu kayıtlar aylık olarak toplanıp ve yıllık yakılan yakıt miktarı hesaplanarak sistemin ne kadar zamanda kurulum maliyetini geri dönüşümü bulunabilmektedir. Manuel olarak sisteme müdahale edilerek kombinin ve radyatörler üzerinde bulunan selenoid valflerin açılıp kapatılması da mümkündür. Ayrıca otomatik olarak ayarlanan sıcaklık değerleri ile radyatörler üzerinde bulunan selenoid vanaların kendiliğinden açılıp kapanması sağlanabilmektedir. 




Şekil 7. Bilgisayar yazılımı arayüzü görüntüsü

\section{BULGULAR}

Kombi sistemi 24 saat boyunca sürekli olarak kendi kontrol sistemi ile çalıştırılmıştır. Geliştirilen otomasyon sistemi yardımıyla tüm veriler; ortam sıcaklığı, ortam nemi, petek sıcaklığı, basınç ve kazanın yaktığı yakıt miktarları kayıt altına alınmıştır. Örnek olarak Tablo 1' de kayıt edilen veriler verilmiştir.

Tablo 1. Kombinin normal çalışması durumda elde edilen veri örneği

\begin{tabular}{|l|c|c|c|c|c|}
\hline & Mutfak & Salon & Çocuk Odas1 & Oturma Odas & Yatak Odas1 \\
\hline Ortam Sıcaklığ $\left({ }^{0} \mathrm{C}\right)$ & 23,1 & 22,9 & 23,5 & 22,5 & 22,2 \\
\hline Ortam Nemi $(\% \mathrm{Rh})$ & 43,3 & 43,7 & 44,0 & 42,4 & 42,1 \\
\hline Petek Sıcaklığ1 $\left({ }^{\circ} \mathrm{C}\right)$ & 36,4 & 36,2 & 36,1 & 36,3 & 36,0 \\
\hline Vana & Açık & Açık & Açık & Açık & Açık \\
\hline
\end{tabular}

Not: Sistem Basınc1 1,535 bar ve Doğalgaz Yakıt Tüketimi 10,2 m³/gün'dür.

Şekil 8' deki grafikte görüldüğü gibi 24 saat boyunca manuel modda sistemden gelen veriler 30 dakika aralıklarla kayıt edilmiştir. Bu çalışma düzeneğinde 30 günlük veriler elde edilerek ne kadarlık enerji tüketimi olduğu hesaplanmıştır. 
Şahin, V.\& Şahin, M. E.

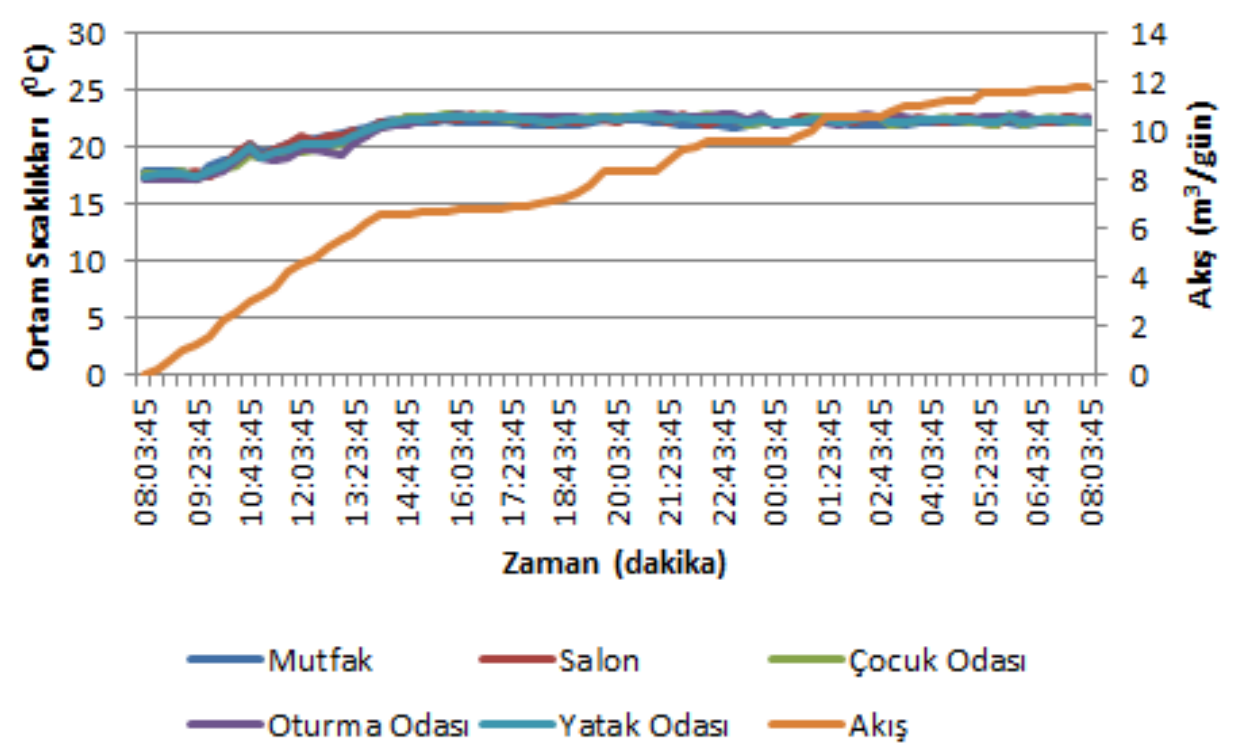

Şekil 8. Kombinin normal çalışması durumunda 1. deneye ait grafik

Gerçekleştirilen sistem yardımıyla kombinin çalışma sistemi otomatik olarak kendiliğinden kontrolü bir şekilde çalışması için oda sıcaklıkları $24{ }^{\circ} \mathrm{C}$ olacak şekilde ayarlanmıştır. Bu durumda ortam sıcaklığı, ortam nemi, petek sıcaklığı, basınç ve kazanın yaktığı yakıt miktarları kayıt altına alınmıştır. Örnek olarak Tablo 2' de kayıt edilen veriler verilmiştir.

Tablo 2. Odaların ortam sıcaklıklarının $24{ }^{\circ} \mathrm{C}$ olacak şekilde ayarlandığında kayıt edilen veri örneği

\begin{tabular}{|l|c|c|c|c|c|}
\hline & Mutfak & Salon & Çocuk Odası & Oturma Odası & Yatak Odası \\
\hline Ortam Sıcaklığ $\left({ }^{\circ} \mathrm{C}\right)$ & 25,4 & 24,1 & 24,3 & 23,8 & 23,5 \\
\hline Ortam Nemi $(\% \mathrm{Rh})$ & 43,0 & 43,2 & 43,5 & 42,5 & 43,1 \\
\hline Petek Sıcaklı̆̆ $\left({ }^{\circ} \mathrm{C}\right)$ & 33,5 & 33,6 & 33,7 & 33,0 & 33,3 \\
\hline Vana & Kapalı & Kapalı & Kapalı & Açık & Açık \\
\hline
\end{tabular}

Not: Sistem Basıncı 1,533 bar ve Doğalgaz Yakıt Tüketimi 8,8 m³/gün’dür.

Tablo 2'de görüldüğü üzere sistem belirlenen sıcaklık değerlerine ulaştığında selenoid vanalar kapalı konuma geçmiştir. Eğer ayarlanan oda sıcaklık değerinin altına düşerse selenoid vanalar açılarak radyatöre sıcak su girişine izin verilecektir. 
Şekil 9' de ki grafikte görüldüğü gibi 24 saat boyunca otomatik modda sistemden gelen veriler 1 saat ara ile kayıt edilmiştir. Bu çalışma düzeninde 30 günlük veriler elde edilerek ne kadarlık enerji tüketimi olduğu hesaplanmıştır.

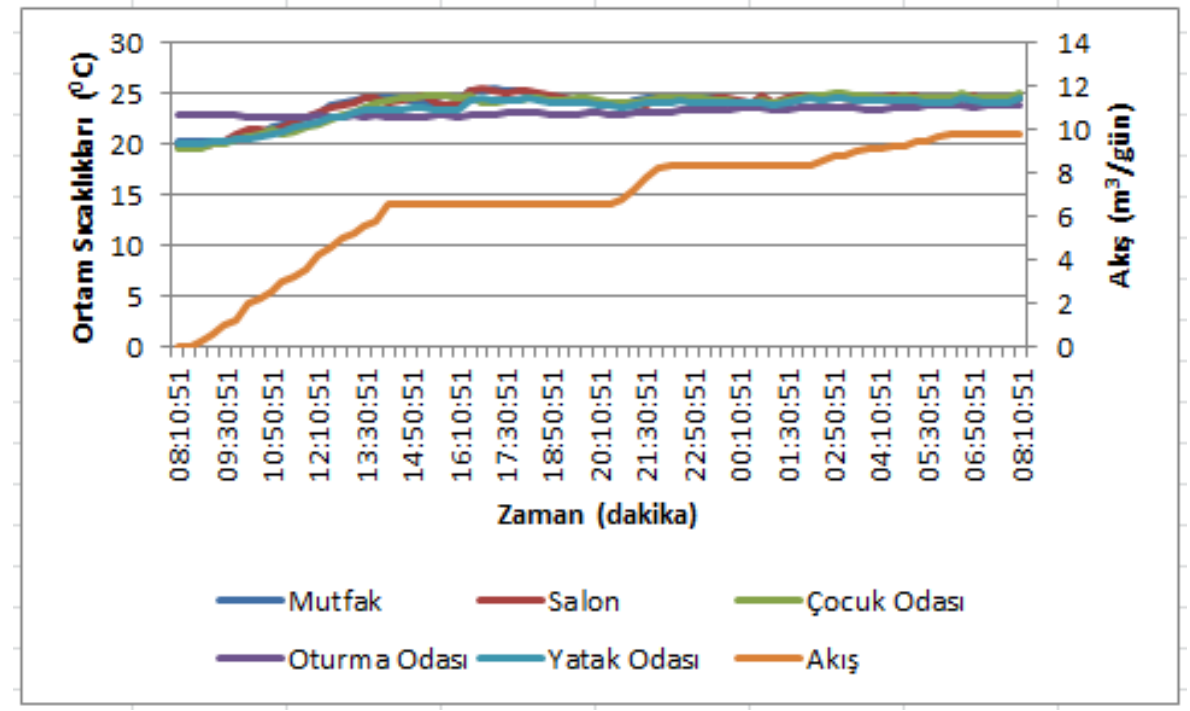

Şekil 9. Odaların ortam sıcaklığının $24^{\circ} \mathrm{C}$ ' ye ayarlı olduğu durumda 2 . deneye ait grafik

Şekil 10'daki grafikte de 30 günlük manuel kullanım, 30 günlük otomatik kullanım verileri yer almaktadır. Elde edilen veriler sonucunda görüldüğü üzere otomatik modda çalışma sonucu akış miktarında düşüş olduğu gözle görülmektedir.

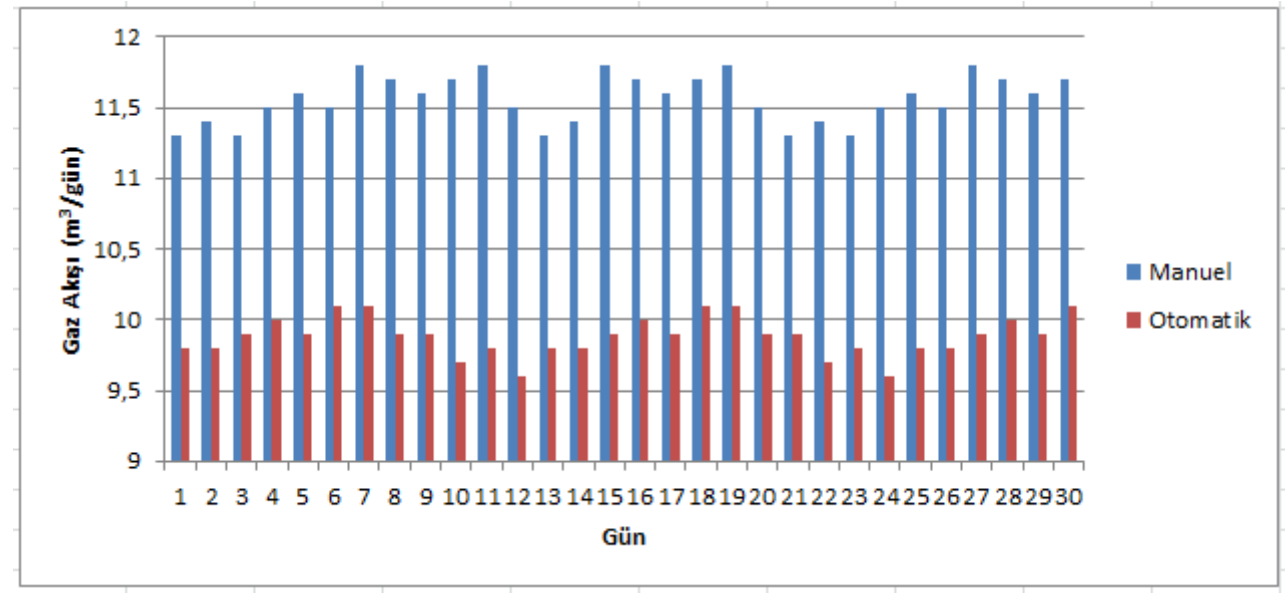

Şekil 10. 30 günlük manuel ve otomatik kullanıma ait yakıt tüketim grafiği

\section{TARTIŞMA VE SONUÇ}

Tasarlanan bu sistem sayesinde gaz yakıtlı sistemlerin çalışması otomatik olarak kablosuz uzaktan kontrol edilebilmektedir. İstendiği zaman çalışmasına manuel olarak da müdahale edilebilmektedir. Odalarda bulunan kontrol ünitelerindeki sıcaklık sensörleri ile 
ortam sıcaklığı algılanarak radyatör sıcak su girişleri selenoid vana sayesinde otomatik olarak açılıp kapanabilmektedir. Bu kontrol mekanizması ile farklı konumlarda bulunan odalardaki 1sının dengelenmesi için sıcak olan odalara az miktarda, soğuk olan odalara ise fazla miktarda sıcak su girişi sağlanarak eşit bir ısı dağılımı sağlanmaktadır. Bu sayede kombinin fazladan çalışması önlenerek harcanan enerji miktarında düşüş imkânı doğmuştur. Akış sensörü yardımıyla sistemin harcadığı yakıt miktarı görülmektedir. Sistemin otomatik kontrollü çalışması sonucunda \%18 oranında bir yakıt tasarrufu sağlanmıştır. Bu sayede tüketilen enerjinin yönetimi ile verimli bir şekilde kullanılması mümkün hale gelmiştir. Geliştirilen bu sistem bir doğalgaz kombi ünitesine uygulandığında aylık \%18 yakıt verimi ile bugün ki şartlarda yaklaşık olarak 25 ayda kendi maliyetini karşılamaktadır.

\section{REFERENCES / KAYNAKLAR}

Ardehali, M. M., Saboori, M. \& Teshnelab, M. (2004). Numerical simulation and analysis of fuzzy PID and PSD control methodologies as dynamic energy efficiency measures. Energy Conversion and Management, 45, 19811992.

Arduino. (2020). Erişim tarihi: 11.11.2020, https://tr.wikipedia.org/wiki/Arduino

Aosong Electronics. (2010). Digital-output relative humidity \& temperature sensor/modüle. Erişim tarihi: 16.12.2020, https://www.sparkfun.com/datasheets/Sensors/Temperature/DHT22.pdf

Badamasi, Y. A. (2014). The working principle of an Arduino. 11th International Conference on Electronics, Computer and Computation (ICECCO). doi:10.1109/ICECCO.2014.6997578

Chen, W. H., Chung, Y. C. \& Liu, J. L. (2005). Analysis on energy consumption and performance of reheating furnaces in a hot strip mill. International Communications in Heat and Mass Transfer, 32, 695-7067.

Christoffersen, L. B., Larsen, A. \& Togeby, M. (2006). Empirical analysis of energy management in Danish industry. Journal of Cleaner Production, 14, 516-526.

Curtis, M. \& Khare, A. (2004). Energy conservation in electric utilities: An opportunity for restorative economics at SaskPower. Technovation 24, 395-402.

Hepbasli, A. \& Ozalp, N. (2003). Development of energy efficiency and management implementation in the Turkish industrial sector. Energy Conversion and Management, 44, 231-249.

Karagiorgasa, M., Tsoutsosb, T., Drosoua, V., Pouffaryc, S., Paganod, T., Larae, G. L. \& Mendes, J. M. M. (2006). HOTRES: Renewable energies in the hotels. An extensive technical tool for the hotel industry. Renewable and Sustainable Energy Reviews, 10, 198-224.

Kolokotsa, D., Kalaitzakis, K., Antonidakis, E. \& Stravrakakis, G. S. (2002). Interconnecting smart card system with PLC controller in a local operating network to form a distributed energy management and control system for buildings. Energy Conversation and Management, 43, 119-134.

Liu, S., Yuan, Z. \& Chen, Y. (2016). Design of smart wireless temperature measurement system based on NRF24L01. International Journal of Advanced Computer Science and Applications, 7(2). 
nRF24L01 RF Modülü. Erişim tarihi: 11.11.2020, https:/www.robotistan.com/smd-nrf24101-24ghz-transceivermodul-24ghz-alici-verici-modul

Önüt, S. \& Soner, S. (2006). Energy efficiency assessment for the Antalya Region hotels in Turkey. Energy and Buildings, 38, 964-971.

Şahin V., İpek O., Başoğul Y., Gürel, B. \& Keçebaş, A. (2017). Remote control-based energy management for energy savings in a central heating system. Environmental Progress Sustainable Energy, 36, $600-609$. https://doi.org/10.1002/ep.12483

Zhelev, T. K. (2005). Water conservation through energy management. Journal of Cleaner Production, 13, 13951404. 